\title{
Prosopometamorphopsia secondary to a left splenium of the corpus callosum infarct
}

\author{
Tamara Barghouthi, ${ }^{1}$ Nada El Husseini ${ }^{2}$
}

${ }^{1}$ Neurology, Wake Forest Baptist Medical Center, Winston-Salem, North Carolina, USA

${ }^{2}$ Neurology, Wake Forest Baptist Medical Center, Winston-Salem, North Carolina, USA

Correspondence to Dr Nada El Husseini, nelhusse@wakehealth.edu

Accepted 18 April 2018

\section{DESCRIPTION}

A 67-year-old right-handed woman with a medical history of coronary artery disease, hyperlipidaemia, hypertension and diabetes mellitus presented with seeing peoples' faces distorted on the left side. When she saw faces in person or watched images of people on television, she noted the left eye on faces appeared to be moving to the side and upwards. She did not see any distortion when looking at her own face in a mirror or when looking at photographs of faces. She had no difficulty recognising faces and nothing other than faces appeared distorted to her. Her neurological examination was normal. Her ophthalmological examination was also unremarkable. Brain MRI performed 2 months after symptom development showed a subacute infarct in the left aspect of the splenium of the corpus callosum (figure 1A).

The remainder of her stroke workup included transthoracic echocardiogram with normal systolic function and no evidence of an atrial shunt, MR angiography of the head and neck which showed no significant vessel stenosis, haemoglobin A1c of 7.5 and total cholesterol of 120 with low-density lipoprotein (LDL) of 24. She was started on aspirin $325 \mathrm{mg}$ daily for secondary stroke prevention. Repeat MRI of the brain completed 4 months after the first brain imaging showed expected evolution of a remote infarct along the left splenium (figure 1B). At that time, her symptoms had improved but not completely resolved. At 1 year, her symptoms had resolved completely.

Prosopometamorphopsia is a rare condition in which faces are perceived as distorted by the viewer
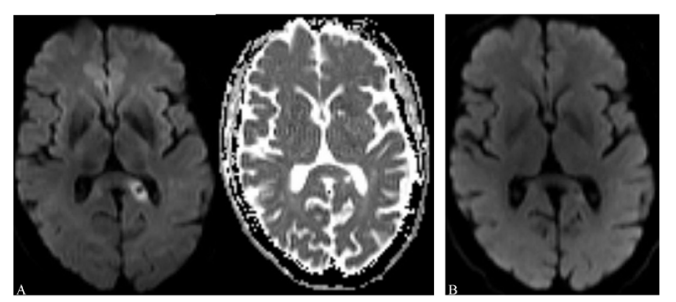

Figure 1 (A) Diffusion-weighted MRI imaging 2 months after onset of prosopometamorphopsia showing a subacute infarct in the left splenium of the corpus callosum. There was no ADC correlate suggesting that the lesion is subacute. (B) Diffusion-weighted MRI imaging 6 months after onset of symptoms showing expected evolution of the infarct. ADC, apparent diffusion coefficient.

\section{Learning points}

- Prosopometamorphopsia is a rare neurological condition in which the faces of other people or part of the face are perceived as distorted and may occur with lesions affecting the retrosplenium, putamen, retina, and temporal, parietal and occipital lobes.

- The perceived facial distortion secondary to lesions of the retrosplenium can be ipsilateral or contralateral to the side of the lesion.

- Prosopometamorphopsia can be the only manifestation of a stroke of the splenium of the corpus callosum.

and has been seen in patients with lesions affecting the retina, retrosplenium, putamen, and temporal, parietal and occipital lobes indicating these structures play important roles in facial processing. ${ }^{12}$ The exact neural basis of prosopometamorphopsia remains unclear, but may involve abnormal activity in face-selective areas in the ventral occipitotemporal pathway. ${ }^{3}$ Cases of unilateral prosopometamorphopsia secondary to lesions of the retrosplenium are rare and can be ipsilateral or contralateral to the side of the lesion. ${ }^{12}$

Contributors TB contributed to conduct, reporting, acquisition of data or analysis and interpretation of data. NE contributed to planning, conduct, conception and design, acquisition of data or analysis and interpretation of data.

Funding The authors have not declared a specific grant for this research from any funding agency in the public, commercial or not-for-profit sectors.

Competing interests None declared.

Patient consent Obtained.

Provenance and peer review Not commissioned; externally peer reviewed.

(C) BMJ Publishing Group Ltd (unless otherwise stated in the text of the article) 2018. All rights reserved. No commercial use is permitted unless otherwise expressly granted.

\section{REFERENCES}

1 Funatsu N, Hayakawa M, Tokuda N, et al. Transient prosopometamorphopsia restricted to the left eye caused by ischemia at the right splenium of the corpus callosum. Intern Med 2017;56:2933-5.

2 Miwa $\mathrm{H}$, Kondo T. Metamorphopsia restricted to the right side of the face associated with a right temporal lobe lesion. J Neurol 2007;254:1765-7.

3 Dalrymple KA, Davies-Thompson J, Oruc I, et al. Spontaneous perceptual facial distortions correlate with ventral occipitotemporal activity. Neuropsychologia 2014;59:179-91. 
Copyright 2018 BMJ Publishing Group. All rights reserved. For permission to reuse any of this content visit http://group.bmj.com/group/rights-licensing/permissions.

BMJ Case Report Fellows may re-use this article for personal use and teaching without any further permission.

Become a Fellow of BMJ Case Reports today and you can:

- Submit as many cases as you like

- Enjoy fast sympathetic peer review and rapid publication of accepted articles

Access all the published articles

- Re-use any of the published material for personal use and teaching without further permission

For information on Institutional Fellowships contact consortiasales@bmjgroup.com

Visit casereports.bmj.com for more articles like this and to become a Fellow 